\title{
Surface complexation studied via combined grazing-incidence EXAFS and surface diffraction: arsenate on hematite (0001) and (10-12)
}

\author{
G. Waychunas • T. Trainor • P. Eng • J. Catalano • \\ G. Brown • J. Davis $\cdot$ J. Rogers $\cdot$ J. Bargar
}

Published online: 3 November 2006

(C) Springer-Verlag 2006

The authors have found an error in Fig. 7 of the above article. Please find the correct Fig. 7 with the corresponding caption below. Throughout the article the (10-12) plane noted should have been identified as the (1-102) plane.

The online version of the original article can be found at http://dx.doi. org/10.1007/s00216-005-3393-z.

\footnotetext{
G. Waychunas $(\triangle)$

Lawrence Berkeley National Laboratory,

Berkeley, CA 94720, USA

e-mail: gawaychunas@lbl.gov

T. Trainor

University of Alaska Fairbanks,

Fairbanks, AK 99775, USA

P. Eng

CARS, Argonne National Laboratory,

Argonne, IL 60637, USA

J. Catalano

Environmental Chemistry Division,

Argonne National Laboratory,

Argonne, IL 60637, USA

G. Brown

Stanford University,

Stanford, CA 94305, USA

J. Davis

US Geological Survey,

Menlo Park, CA 94025, USA

J. Rogers $\cdot$ J. Bargar

Stanford Synchrotron Radiation Laboratory,

Stanford, CA 94305, USA
}

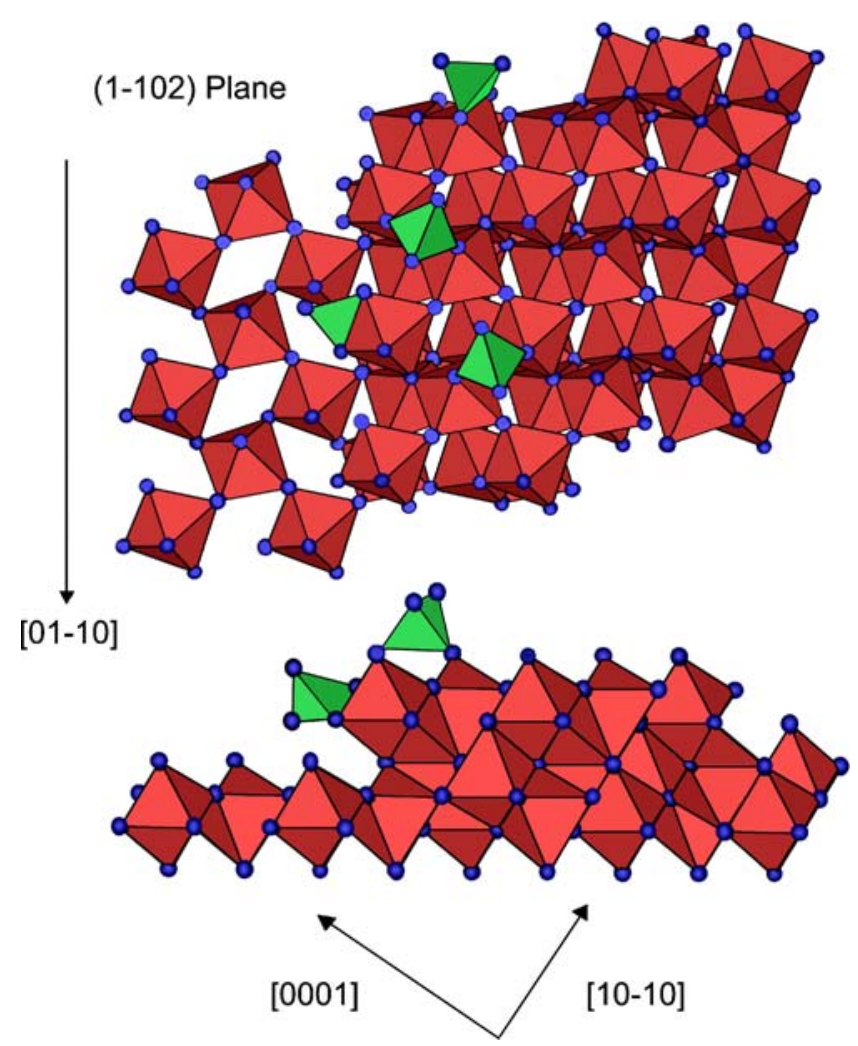

Fig. 7 Possible arsenate complexation geometries for the hematite (1-102) wet surface. Top: view from above plane. Arsenates attach either to two $\mathrm{Fe}$ octahedra at oxygen corners, or to a single $\mathrm{Fe}$ octahedron edge. The edge complex appears only at the side of a growth step. Bottom: Side view of the same complexation geometries 